\title{
Research Status of Uygur Language as the Second Language Teaching Based on Bibliometric Analysis
}

\author{
Fangli Yuan ${ }^{1, a}$ and Xiadiya Yibulayin ${ }^{2, b^{*}}$ \\ ${ }^{1}$ Chinese Language Institute, Xinjiang University, Hutubi County, Xinjiang, 830046, China \\ ${ }^{2}$ Chinese Language Institute, Xinjiang University, Urumqi, Xinjiang, 830046, China \\ ayfl_merely@163.com, bxadiya49@hotmail.com
}

\section{Keywords: Bibliometrics; Uygur Language; Second language teaching}

\begin{abstract}
With the development of Uygur language courses, the study of Uygur language as the second language teaching is increasing. This paper studied the development and research significance of Uyghur language as the second language teaching research from 2001 to 2015, and then put forward some suggestions on the Uyghur language as the second language teaching research, in order to provide reference for further research in this field. The Chinese periodicals, and the periodicals and journals collected by libraries about the Uygur language as the second language teaching which are included in the CNKI are taken as the data sources, and the bibliometric method is used to carry out the statistical analysis for data sources, research methods, literature research contents, literature research methods, literature date analysis, periodical characteristics analysis and author characteristics analysis. The results show that the literature of the Uygur language as the second language is not evenly distributed in the acquisition and teaching. Through the analysis of the structure distribution of the periodicals, it is concluded that the research development in this field is not mature enough and is at the stage of development. Through the research on the number of papers published by authors, it is concluded that the core author group in the research field of the Uygur language as the second language teaching has not yet been fully formed, and the research development in this field is still to be mature. Through the study of the cooperation rate of the author, it is concluded that the literature cooperation intensity of Uygur language as a second language teaching research field is low and the strength is not enough. Conclusions: a), More attention has been paid to this major, but the Uyghur language as the second language teaching has not been comprehensively studied in China. Its theoretical research relatively lags behind. b), There is not enough research on this subject, and the scale of teaching and the research intensity are disproportionate. The research status of Uygur language teaching as the second language teaching is not optimistic. Relevant units and scholars need to pay more attention to this field and promote the development of this field.
\end{abstract}

\section{Introduction}

There is a category in the language teaching in China, which is the minority language teaching for Chinese students or foreigners. In China, the Uighur, Mongolian, Tibetan, Korean, Kazakh and other languages are taken as the second language teaching. Among them, Uyghur as the second language teaching includes Uyghur language teaching for non Uygur students, such as Han nationality, Hui nationality and other ethnic groups and Uyghur Language Teaching for foreigners. Uygur language, as the second language teaching research, has been a history of more than half a century since the founding of new China. During this period, our Uygur language as the second language teaching has gone through the following stages: initial stage, slow development stage and comprehensive recovery stage. Especially in the past thirty years, it has made rapid progress and achieved fruitful results. Therefore, it is very necessary to describe and present its research status so as to play a certain construction role in the healthy and long-term development of the major. 


\section{Research Methods and Data Sources}

Research Methods. Bibliometric analysis is based on the attributes of all aspects of literature and discusses and predicts the laws and phenomena of science and technology through mathematical and statistical methods. The common research objects of bibliometrics include the parts of the literature characteristics, such as the author, the citation, the vocabulary and so on[1]. This paper deals with the literature data through the literature statistics tool Excel, and analyzes the data sources, research methods, literature research content, literature research methods, literature age, periodical characteristics and author characteristics by drawing tables, line chart, and other related charts. Combined with the results of statistical analysis, we use the method of combining quantitative and qualitative analysis to form an analysis report and explore the research status of Uyghur language as a second language.

Data Sources. The Uygur language as the second language teaching is a class of language teaching. In this paper, the periodicals about Uygur language as the second language teaching included by CNKI are taken as the data sources, and the full text retrieval is set as the "literature source". The theme is taken as the retrieval item, and "the research status of Uygur language as the second language teaching based on Bibliometric analysis", "the Uygur language" and "the Uygur language" containing "the second language teaching" are taken as the retrieval words to match accurately. The time limit is from 2001 to 2015, and we should retrieve three times. A total of 268901 articles are obtained in this search. Through artificial screening, 61 related articles are obtained after removing the articles that are not related to the Uygur language as the second language teaching. Secondly, through artificial reading of Uighur periodicals and journals, 29 related articles are obtained. After the addition of the former to the latter, the total number of articles related to Uygur language as the second language teaching(Uygur and Chinese) is 90. The following figure is the proportion of the two.

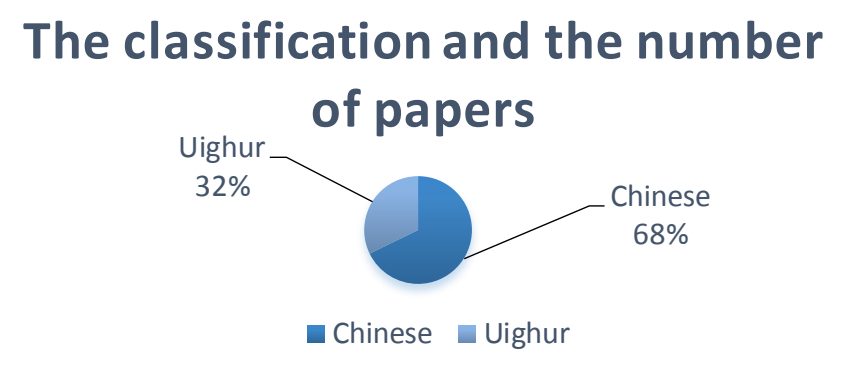

\section{Analysis of the Research Status of Uygur Language as the Second Language Teaching}

After the founding of new China, in order to cultivate bilingual cadres in minority areas, the Party and the state set up the Uygur language major in Minzu University of China and Xinjiang University. By now, the scale of enrollment and the establishment of colleges and universities are constantly expanding. The importance of Uygur language as second language teaching is becoming more and more obvious in promoting the national unity, social stability, economic prosperity and the common development of all ethnic groups. In order to improve the teaching level and quality of Uygur language, and enrich teaching contents, methods and courses, we will use data to show the research achievements and current situation of Uyghur language as the second language teaching.

Content of Literature Research. Corder (1967) The Significance of Learners' Errors and Selinker (1972) Interlanguage are considered as the marks of the establishment of second language acquisition research. We take the Uygur language as the second language teaching, and the content is divided into two aspects: teaching and acquisition. We can clearly see the proportion of the two through the literature statistics charts, as shown in the following figure. 


\section{Classification of literature content} and quantity of literature

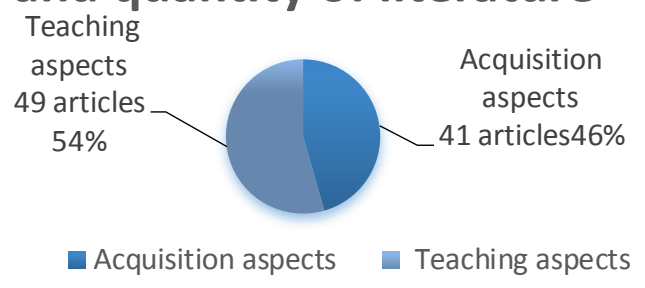

The first one is the study on acquisition. Ellis (1994) further summed up the second language acquisition framework in four aspects[2]: The language features of the learners, the external and internal factors that influence the learners' acquisition of the second language, and the individual differences of the learners. The language features of the learners include the errors of the learners, the acquisition order and the development sequence, the language variation of the learners, the pragmatic features and so on. Individual differences of learners include learners' learning motivation, learning strategies, and so on. The external factors that affect the learner's acquisition of the second language include the social environment, language input, interaction and so on. The internal factors that affect the learner's acquisition of the second language include the transfer of the learner's mother tongue, the learning process, the communicative strategy, the universal grammar and so on. According to this theory and the analysis of the related literature of Uygur language as the second language teaching, the research on the Uygur language as the second language teaching in acquisition can be divided into five contents: The factors affecting the second language acquisition, the status of the second language acquisition, the learning ability, the individual differences of the learners and the language characteristics of the learners. From the figure, we can know that the factors affecting the second language acquisition, the individual differences of the learners and the language characteristics of the learners are the main contents of the acquisition research content, showing a situation of tripartite confrontation trend.

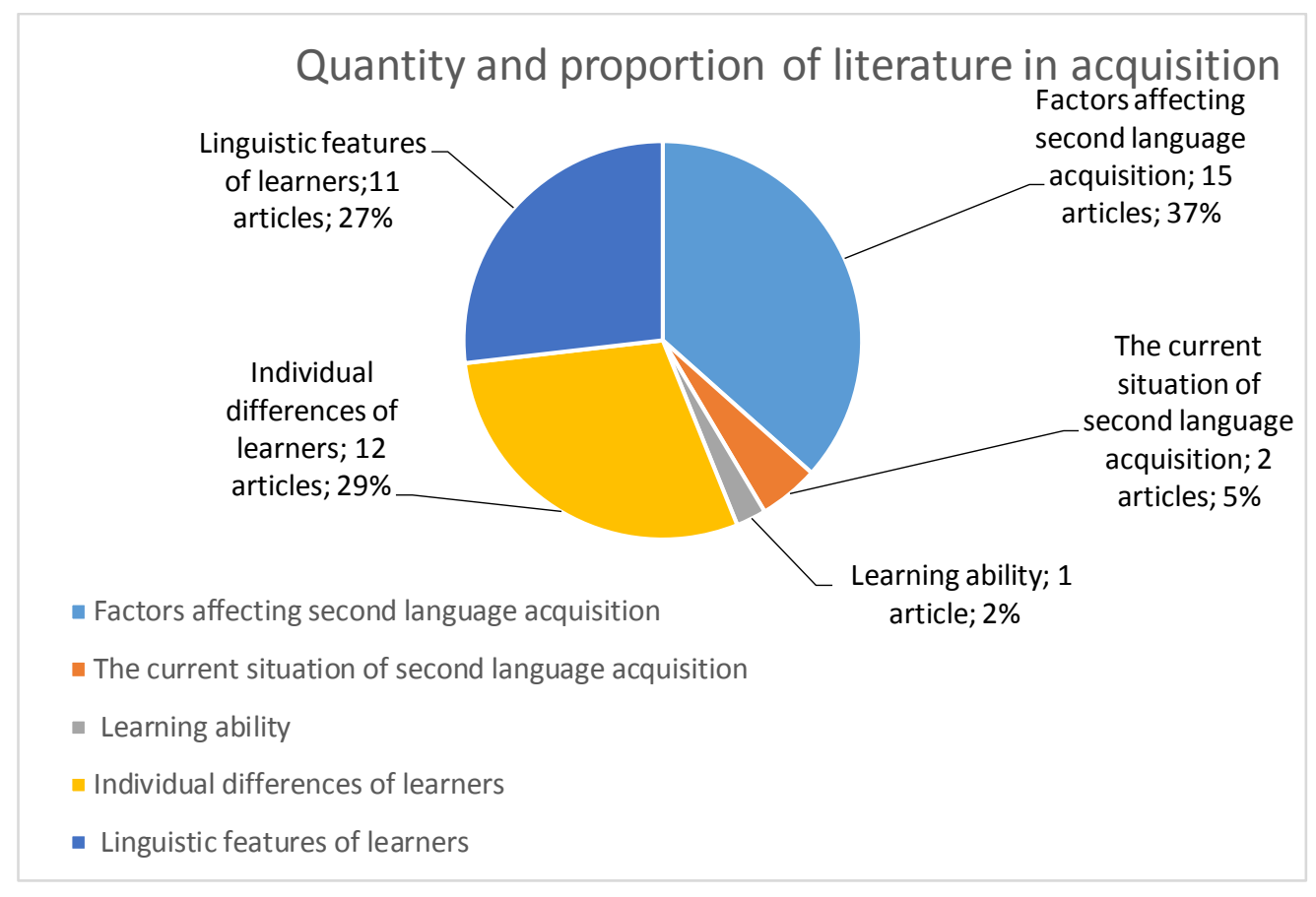

The second one is the research on teaching. According to the statistical analysis of the literature, the literature content that studies the Uygur language as the second language teaching is composed of teaching methods, teaching devices, teaching strategies, teaching systems, the current situation of 
teaching, teaching quality, language culture teaching and language testing system. From the perspective of teaching content, it is divided into phonetic teaching, grammar teaching, vocabulary teaching and writing teaching. From the figure, we can know that the proportion of phonetic teaching and teaching strategies is the largest, and the proportion of phonetic teaching and teaching strategies is $35 \%$ and $19 \%$ respectively. It can also be seen that the research on the Uygur language as the second language teaching in the teaching aspects is uneven, and the development is not balanced, as shown in the following figure.

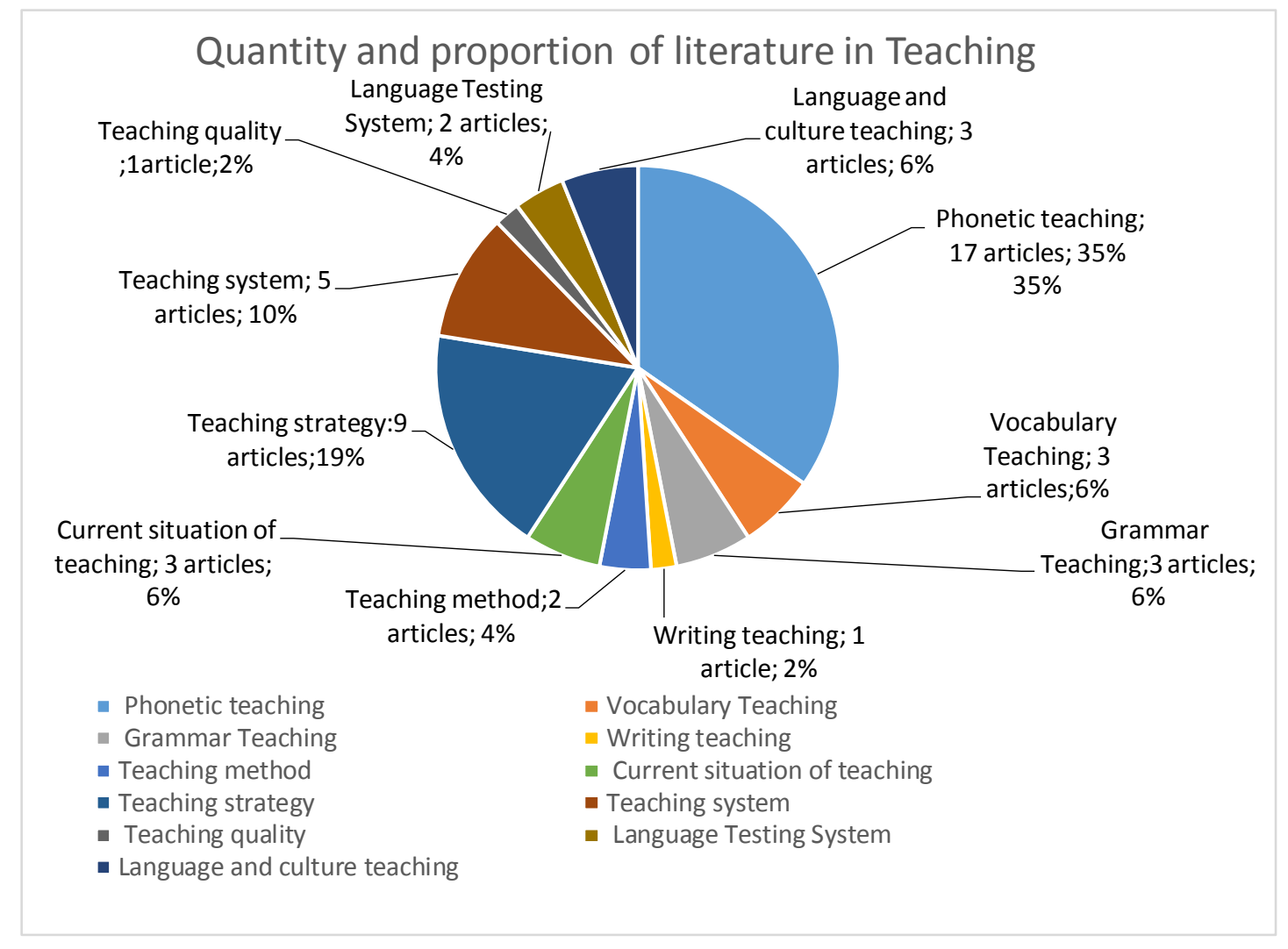

Research Methods. Research methods are the ways, means and methods of scientific research activities. Researchers choose some way of behavior to link themselves with the research object to achieve the research goals. According to the introduction of Lawrence Newman to the sociological research method[3], quantitative research includes experimental research, investigation research, content analysis, statistical data analysis, literature research, etc. Qualitative research includes field studies including interviews and field observation, historical comparative studies, case studies, etc. According to this method, Uyghur language as a second language teaching research method can be divided into three research methods: qualitative research, quantitative research and the combination of quantitative and qualitative research, as shown in the following figure.

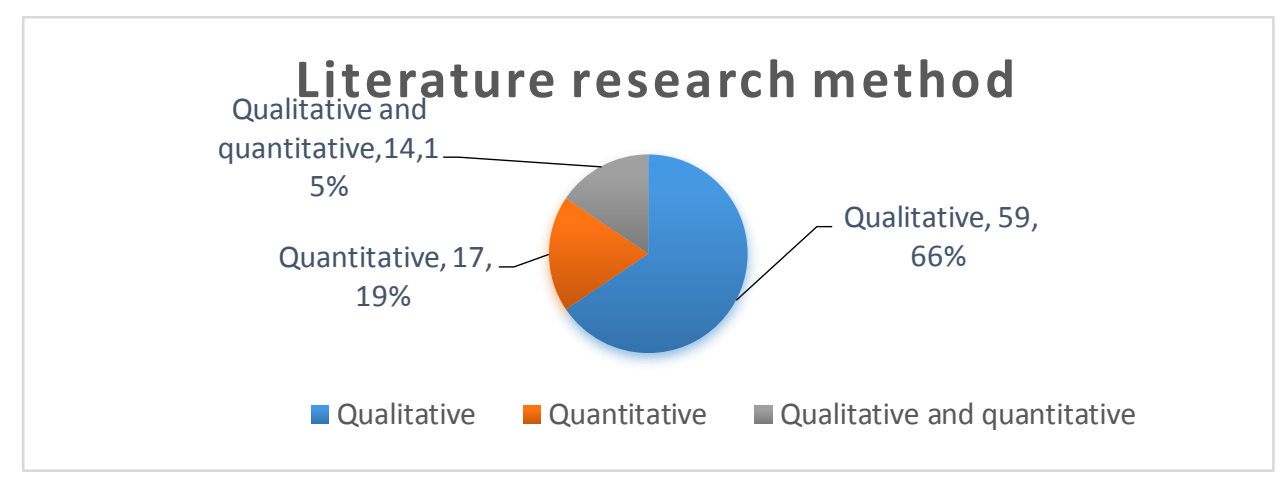

According to the above pie chart, the literature about the research of Uygur as the second 
language teaching is almost qualitative research, which accounts for $66 \%$. The quantitative research accounts for $19 \%$. The literature containing qualitative research and quantitative research accounts for $15 \%$. The literature using qualitative research method is almost descriptive analysis and inductive analysis on research content in the process of collecting data. However, a large part of quantitative research is using deductive analysis on research content by questionnaires or other means. The qualitative and quantitative research uses qualitative methods and quantitative methods. The research of literature about the Uygur as the second language teaching will be done by quantitative methods and qualitative methods.

Analysis of Years of Literature. The total amount of literature can absolutely reflect production of research activities within a certain period of time. It is an important indicator to evaluate research activities. The table and bar charts were drawn based on literature published from 2001 to 2015 about the Uygur as the second language teaching through literature retrieval and statistical analysis. According to the graph, the output of Chinese literature and the Uygur literature was so low from 2001 to 2015. The average output was 6 papers. It was found that the amount of Chinese literature about the Uygur as the second language teaching was fluctuating and low before 2013 according to the graph. It presented a waving trend. The amount of the Chinese literature developed fast after 2013 and it presented an increasing trend. The amount of Uygur literature published from 2004 to 2009 was very high but its radix was small. It was suggested that the Uygur as the second language teaching didn't got enough focus from 2001 to 2012. The development state of the Uygur as the second language teaching can be seen through the line chart. It presents an upward trend but its development is fluctuating and slow. It has developed rapidly since 2012. Therefore, we can see that people gradually focus on the research of the Uygur as the second language teaching through the chart as the chart shows.

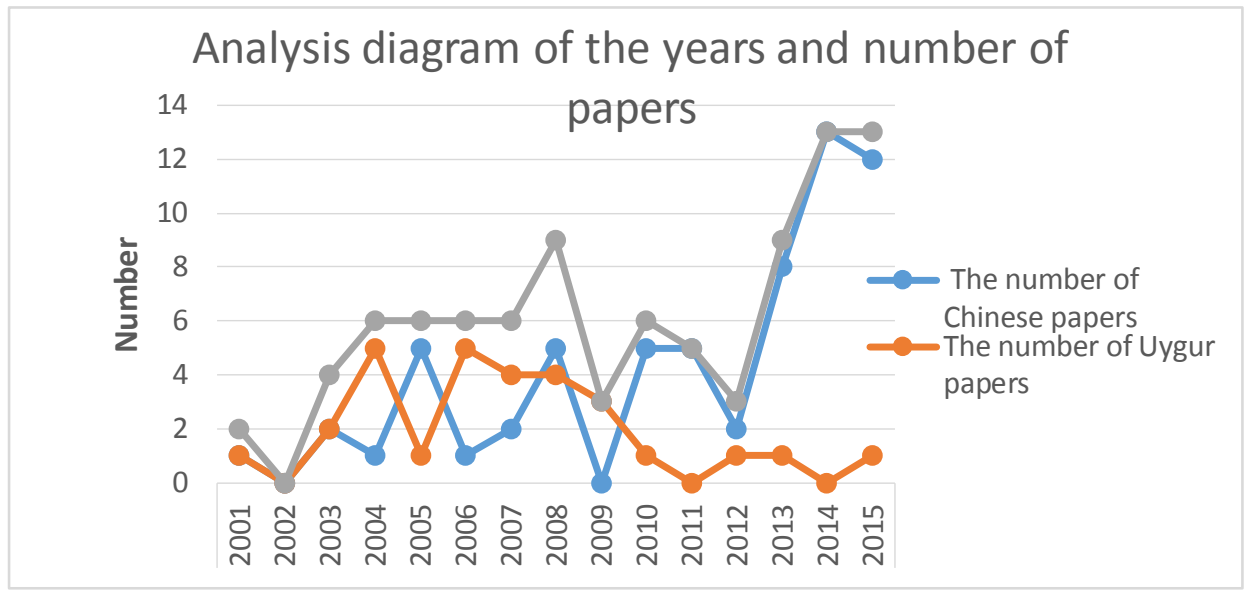

Analysis on Characteristics of Journals. The literature ( Chinese and Uygur ) about the Uygur as the second language teaching published from 2001 to 2015 was in forty kinds of journals. The journals whose publishing amount is at top ten are listed among 40 kinds of journals in the table. The journal that has the most papers about the Uygur as the second language teaching are published is Language and Interpretation according to the table. The amount is 22 . The second one is Journal of Xinjiang Normal University. The amount is 9. The third one is Journal of Xinjiang University. The amount is 5 . There are 56 papers in the top ten journals. It accounts for $60 \%$. Therefore, it can be seen that the authoritative journals are Language and Interpretation, Journal of Xinjiang Normal University and Journal of Xinjiang University. It is known that the amount of master's thesis is 4 during collecting process. It accounts for $4 \%$. The amount is the same as that of Journal of Kashgar Normal College. It shows that students except for scholars start to gradually focus on the research of the Uygur as the second language teaching. 


\begin{tabular}{|c|c|c|c|}
\hline Category of periodicals & $\begin{array}{c}\text { Number of } \\
\text { papers }\end{array}$ & $\begin{array}{c}\text { Proportion } \\
\text { of literature }\end{array}$ & Ranking \\
\hline Language and Translation & 22 & $24 \%$ & 1 \\
\hline $\begin{array}{c}\text { Journal of Xinjiang Normal } \\
\text { University }\end{array}$ & 9 & $10 \%$ & 2 \\
\hline Journal of Xinjiang University & 5 & $6 \%$ & 3 \\
\hline $\begin{array}{c}\text { Journal of Kashgar Normal } \\
\text { University }\end{array}$ & 4 & $4 \%$ & 4 \\
\hline $\begin{array}{c}\text { Journal of Xinjiang Education } \\
\text { College }\end{array}$ & 4 & $4 \%$ & 5 \\
\hline Journal of Hotan Normal College & 3 & $3 \%$ & 6 \\
\hline Journal of Ili Normal College & 3 & $3 \%$ & 7 \\
\hline $\begin{array}{c}\text { Journal of Xinjiang Police } \\
\text { Officers' Academy }\end{array}$ & 2 & $2 \%$ & 8 \\
\hline $\begin{array}{c}\text { Journal of Xinjiang Vocational } \\
\text { College }\end{array}$ & 2 & $2 \%$ & 9 \\
\hline Study of Bilingual Education & 2 & $2 \%$ & 10 \\
\hline \multicolumn{2}{|c|}{} & & \\
\hline
\end{tabular}

The Bradford Law is usually used to study the structural distribution of journals[4]. According to Bradford Law, the journals about the Uygur as the second language teaching are ranked in descending order based on the number of papers. They are called core area, related area and fringe area. The number in every area is nearly the same. The specific data can be seen in the below table. The proportion about the amount of journals in every area is $1: 5.5: 33.5$, which is not in line with 1 : $\mathrm{n}: \mathrm{n}^{2}$. It shows that the research in this area is not mature enough and it is still in the developing phase.

\begin{tabular}{|c|c|c|c|c|}
\hline Number of papers & Division interval & $\begin{array}{c}\text { Number of } \\
\text { Journals }\end{array}$ & $\begin{array}{c}\text { Proportion of } \\
\text { the number of } \\
\text { Journals }\end{array}$ & $\begin{array}{c}\text { Area } \\
\text { category }\end{array}$ \\
\hline 31 & I-II & 2 & $5 \%$ & Core area \\
\hline 31 & III-XIII & 11 & $28 \%$ & $\begin{array}{c}\text { Related } \\
\text { area }\end{array}$ \\
\hline 28 & XIV-IVX & 27 & $67 \%$ & Fringe area \\
\hline
\end{tabular}

Analysis on Characteristics of Authors. The research objects about analysis on characteristics of authors is nearly about publishing amount, cooperation rate, the situation of research units, etc.

The first one is publishing amount. Characteristics of authors are analyzed by collecting data and using Excel. The number of papers published by each author is ranked in a descending order. The authors who are in top ten position are listed in the following table. 


\begin{tabular}{|c|c|c|c|}
\hline Name of Authors & $\begin{array}{l}\text { Number of } \\
\text { publishing } \\
\text { papers }\end{array}$ & $\begin{array}{l}\text { Units and } \\
\text { Institutes }\end{array}$ & Percentage \\
\hline Aierken kadeer & 5 & $\begin{array}{l}\text { Xinjiang Normal } \\
\text { University }\end{array}$ & $6 \%$ \\
\hline Zhanfeng An & 5 & $\begin{array}{c}\text { Xinjiang } \\
\text { Agricultural } \\
\text { University }\end{array}$ & $6 \%$ \\
\hline Rexidan Malike & 4 & $\begin{array}{c}\text { Xinjiang } \\
\text { University }\end{array}$ & $4 \%$ \\
\hline Dilibaier Sulaiman & 3 & $\begin{array}{l}\text { Xinjiang Normal } \\
\text { University }\end{array}$ & $3 \%$ \\
\hline Rebiya Abudureyimu & 3 & $\begin{array}{l}\text { Xinjiang Normal } \\
\text { University }\end{array}$ & $3 \%$ \\
\hline Xiadiya Yibulayin & 3 & $\begin{array}{c}\text { Xinjiang } \\
\text { University }\end{array}$ & $3 \%$ \\
\hline Abudureyimu Reheman & 2 & $\begin{array}{c}\text { Xinjiang } \\
\text { University }\end{array}$ & $2 \%$ \\
\hline Aziguri Xialifu & 2 & $\begin{array}{c}\text { Xinjiang } \\
\text { University }\end{array}$ & $2 \%$ \\
\hline Chongrao Cai & 2 & $\begin{array}{l}\text { Xinjiang Normal } \\
\text { University }\end{array}$ & $2 \%$ \\
\hline Dilibaier Mijiti & 2 & $\begin{array}{l}\text { Xinjiang Normal } \\
\text { University }\end{array}$ & $2 \%$ \\
\hline
\end{tabular}

It can be seen from the table that these ten are high-yield writers of this study among 82 high-yield writers. The number of their publishing papers is more than 2 . The number of other authors is only 1 .

Characteristics of authors and research status about the Uygur as the second language teaching can be analyzed by Lotka Law and Price Law based on statistical results.

The Lotka Law[5]: It describes the relationship between the number of scholars and papers that are written by them. It means that the number of authors who write two papers nearly accounts for $1 / 4$ of the number of authors who write one paper. It also means that the number of authors who write three papers should nearly accounts for 1/9 of the number of authors who write one paper. In conclusion, it means that the number of authors who write $\mathrm{N}$ papers should nearly accounts for $1 / \mathrm{n}^{2}$ of the number of authors who write one paper. Meanwhile, the number of authors who write one paper should accounts for $60 \%$ of all the authors. This law is considered to be the first to reveal the relationship between the frequency of the appearance of authors and the amount of literature, and describe the frequency distribution of scientific productivity.

The authors of papers about the Uygur language as the second language teaching are analyzed by this low. From it, we can get: The number of authors who publish 5 papers is $1 / 25$ of the number of authors who publish one paper. The number of authors who publish 4 papers is $1 / 16$ of the number of authors who publish one paper. The number of authors who publish 3 papers is $1 / 9$ of the number of authors who publish one paper. The number of authors who publish 2 papers is $1 / 4$ of the number of authors who publish one paper. In fact, the number of authors who publish 5 papers is $1 / 32 \neq 1 / 25$ of the number of authors who publish one paper. The number of authors who publish 4 papers is $1 / 36 \neq 1 / 16$ of the number of authors who publish one paper. The number of authors who publish 3 papers is $1 / 21 \neq 1 / 9$ of the number of authors who publish one paper. The number of authors who publish 2 papers is $1 / 6 \neq 1 / 4$ of the number of authors who publish one paper. The number of authors who just write one paper accounts for $78 \%>60 \%$ of the number of all the authors. According to the Lotka law, we can know that the greater the proportion of authors who publish one paper in the total number of authors, the lower the maturity of the field. This shows that the Uygur language is in the 
initial stage as the second language teaching and research field, and the research is not deep enough and the maturity is low.

Price law: In the same topic, half of the papers are written by a group of authors with high productive capacity, and the number of the collection of authors is approximately equal to the square root of the total number of authors, that is, authors who publish more than $\mathrm{N}$ papers are the core authors. They should finish half the total of all the professional papers. The minimum number of papers published by the core author $\mathrm{N} \approx 0.749 \sqrt{ } \mathrm{Nmax}$, among them, Nmax is the maximum number of papers published by the author.

The authors of papers about the Uygur language as the second language teaching are analyzed by this low. According to the formula, $\mathrm{N} \approx 2$. So the authors who publish more than 2 papers are the core authors. The number of papers published by the core authors is 49 , accounting for $54 \%$ of the total number of papers, and the proportion of the paper is half of the total number of papers. This conclusion is basically consistent with Price law.

According to Lotka Law and Price Law, the core author group who can do research about the Uygur language as the second language teaching has not yet been fully formed. The development in this research field is not mature yet.

The second one is the author's cooperation rate. The author's cooperation rate is used to analyze the intensity and strength of the literature cooperation in this field. On the one hand, the cooperation rate embodies the cooperation spirit of the author's team, on the other hand, it also shows that scientific research has reached a certain scale and depth. It involves the field of multidisciplinary, which is the need of modern scientific research, and the inevitable phenomenon of the development of modern scientific research to a certain stage. The following table is a statistical table for the literature cooperation rate of the Uygur language as the second language teaching research.

\begin{tabular}{|c|c|c|}
\hline $\begin{array}{c}\text { The number of papers whose authors are } \\
\text { more than one }\end{array}$ & Total & $\begin{array}{c}\text { The Proportion of } \\
\text { cooperation papers }\end{array}$ \\
\hline 19 & 90 & $21 \%$ \\
\hline
\end{tabular}

It can be seen from the table that the number of papers whose authors are more than one is 19 , accounting for $21 \%$ of the total, that is, the cooperation rate is $21 \%$. It shows that the the intensity of literature cooperation of Uygur language as a second language teaching research field is, and the strength is not enough.

The third one is the research unit situation. The table is made based on statistical analysis. The following table is the first 15 units according to the number of papers. It can be seen from the table that the Xinjiang Normal University, Xinjiang University, Kashi Normal University and Xinjiang Agricultural University are the main positions, and the number of papers published accounts for $83 \%$ of the total. This shows that the literature research institutions are more concentrated, and that Uygur language, as a minority language, has a narrow research area. According to the comparison of the tables, the remaining research units have only published the relevant Chinese literature except the first four research units. 


\begin{tabular}{|c|c|c|c|}
\hline Name of unit and organization & $\begin{array}{l}\text { The number } \\
\text { of Chinese } \\
\text { papers }\end{array}$ & $\begin{array}{l}\text { The number of } \\
\text { Uygur papers }\end{array}$ & $\begin{array}{l}\text { Total } \\
\text { number of } \\
\text { papers }\end{array}$ \\
\hline Xinjiang Normal University & 15 & 16 & 31 \\
\hline Xinjiang University & 10 & 9 & 19 \\
\hline Kashi Normal University & 12 & 2 & 14 \\
\hline Xinjiang Agricultural University & 9 & 2 & 11 \\
\hline Hotan Teachers College & 3 & 0 & 3 \\
\hline $\begin{array}{c}\text { Translation Teaching and Research } \\
\text { Section of Frontier Defense Cadre } \\
\text { Training Brigade }\end{array}$ & 2 & 0 & 2 \\
\hline Tarim University & 2 & 0 & 2 \\
\hline $\begin{array}{l}\text { Urumqi Command School of Public } \\
\text { Security Frontier Guards }\end{array}$ & 1 & 0 & 1 \\
\hline $\begin{array}{l}\text { Xinjiang University of Finance and } \\
\text { Economics }\end{array}$ & 1 & 0 & 1 \\
\hline Xinjiang Education Institute & 1 & 0 & 1 \\
\hline Xinjiang Police College & 1 & 0 & 1 \\
\hline Xinjiang Police Officer Academy & 1 & 0 & 1 \\
\hline Xinjiang Institute of Engineering & 1 & 0 & 1 \\
\hline Yili Normal University & 1 & 0 & 1 \\
\hline Information Engineering University & 1 & 0 & 1 \\
\hline
\end{tabular}

\section{Conclusions and Suggestions}

Research conclusions: Since the reform and opening up, with the continuous improvement of functional departments, the demand for the graduates majoring in Uygur language has been increasing year by year, including government agencies, national security forces, public security inspection courts, judiciary, universities, publishing and research institutions. The cultural and publishing sectors of the autonomous region have entered the state of shortage of high level translators. There is an urgent need for high level translators in the field of ideological culture and education. The need for graduates majoring in Uygur language in the mainland is increasing year by year. This paper analyzes the research status of Uygur language as a second language through bibliometrics, and draws the following conclusions: a), Although more attention has been paid to this major, the Uyghur language as the second language teaching has not been comprehensively studied in China, and its theoretical research relatively lags behind. b), There is not enough research on the subject, and the scale of teaching and the strength of research are disproportionate. c), The research status of Uygur language as the second language teaching is not optimistic. Relevant units and scholars need to pay more attention to this field and promote the development of this field.

Relevant suggestions: In view of the lack of the research of Uygur language as the second language teaching, the following suggestions are put forward: a), For the old theory, we should take the essence and discard the dross. For the new theory, we should actively and extensively absorb, bring forth new ideas, and actively explore theoretical innovation. Uygur language is a second language teaching and research system. b), We should connect the theory with the practice and reasonably participate in the research according to the teaching scale, so that the scale of teaching and the strength of research are balanced. c), The government and the education department should introduce relevant policies to encourage and guide the research and development of this field. At the 
same time, the researchers should also break the limitations, and make rational use of the current big data and other scientific methods to enrich the Uygur language as a second language teaching and research system.

\section{Acknowledgements}

This article is the periodic result of social science fund project of the autonomous region, "Research on the Development of Minority Languages in Xinjiang of the 60th Anniversary since the Establishment of the Autonomous Region"(Project number: 2015BYY086) and funding project of the key research base of the Humanities and Social Sciences of the colleges and universities in the Xinjiang Uygur Autonomous Region, "Research on the Uygur Language as the Second Language Teaching Based on the Model of Bilingual Translation Talents Training"(Project number: XJEDU010815C01).

\section{References}

[1] W.H.Deng: Comparative Study of Bibliometrics and Content Analysis[J], Journal of Intelligence(2006)No.5, p.31.(In Chinese)

[2] Y.P.Liu and X.M.Sun: Linguistics and the Theory of Second Language Acquisition[M], Minzu University of China Press, 2010, p.43.(In Chinese)

[3] W.Lawrence Neuman, D.H.Hao(Translation): Social Research Methods: Qualitative and Quantitative Orientation(Fifth Edition)[M], China Renmin University Press, 2007, p.23.

[4] J.Z.Guo: Research on Bibliometrics Analysis Tool Based on CNKI Database[J], Journal of Library Science(2014)No.4, p.115-116.(In Chinese) 